\title{
Competição de variedades de algodão herbáceo para cultivo no agreste pernambucano
}

\author{
Competition of herbaceous cotton varieties for cultivation in \\ agreste of pernambucano
}

'Instituto Agronômico de Pernambuco - IPA. Av. General San Martin, 1371 Bongi, CEP 50761-000, Recife, PE Brasil

*autor correspondente \abel_agro@yahoo.com.br

Francisco Abel Lemos Alves ${ }^{1 *}$, Farnésio de Sousa Cavalcante ${ }^{1}$, Ivan Souto de Oliveira Júnior ${ }^{1}$, Ivan Ferraz ${ }^{1}$, Sérvulo Mercier Siqueira e Silva ${ }^{1}$

RESUMO: O algodão é uma cultura com grande potencial socioeconômico para a região Semiárida do Nordeste do Brasil. O objetivo deste trabalho foi avaliar o desempenho de genótipos de algodão herbáceo (Gossypium hirsutum), cultivados no Agreste de Pernambuco em sistema de sequeiro. O experimento foi conduzido na estação experimental do Instituto Agronômico de Pernambuco-IPA, localizado em Caruaru-PE. Os ensaios foram realizados nos anos de 2016/2017 em delineamento blocos casualizados, com quatro repetições e dez tratamentos. Foram avaliados cinco genótipos de fibras brancas (BRS ARARIPE, CNPA 8H, CNPA GO 2006-1023, CNPA GO 2007-419 e CNPA GO 2007-700) e cinco de fibras coloridas (BRS SAFIRA, BRS RUBI, BRS 200, BRS VERDE, BRS TOPÁZIO) quanto à altura das plantas $(\mathrm{cm})$, estande final ( $\mathrm{n}^{\mathrm{o}}$ plantas.ha-1 $\mathrm{h}^{-1}$, peso do capulho (g) e rendimento de algodão em caroço $\left(\mathrm{kg} \cdot \mathrm{ha}^{-1}\right)$. Os resultados indicam variabilidade significativa pelo teste $\mathrm{F}(\mathrm{P}<0,05)$ entre os genótipos, nos dois anos de cultivo, para todas as características analisadas. O BRS $200(99,50 \mathrm{~cm})$, BRS SAFIRA $(99,31 \mathrm{~cm})$ e BRS TOPÁZIO $(99,24 \mathrm{~cm}) \mathrm{se}$ destacam pelo crescimento em comparação aos outros. O CNPA GO 2007-700 (39.250 plantas. $\mathrm{ha}^{-1}$ ) teve a maior densidade populacional, mas não foi o mais produtivo. O BRS TOPÁZIO $\left(1.388,75 \mathrm{~kg} \cdot \mathrm{ha}^{-1}\right)$ teve o maior rendimento de algodão em caroço comparado aos outros. Os genótipos avaliados possuem potencial de cultivo no Agreste Pernambucano, no entanto, mais estudos precisam ser conduzidos para recomendação dos mais produtivos e adaptados à região.

PALAVRAS-CHAVE: Agricultura familiar de sequeiro, agroenergia, cotonicultura.
ABSTRACT: Cotton is a crop with great socioeconomic potential for the semiarid region of Northeast of Brazil. This work aimed to evaluate the performance of genotypes of herbaceous cotton (Gossypium hirsutum), cultivated in the Agreste of Pernambuco in rainfed system. The experiment was conducted at the experimental station of the Agronomic Institute of Pernambuco-IPA, located in Caruaru-PE. The trials were carried out during the years 2016/2017, in a randomized complete block design, with four replications and ten treatments. We evaluated five white fiber genotypes (BRS ARARIPE, CNPA 8H, CNPA GO 2006-1023, CNPA GO 2007-419 and CNPA GO 2007-700) and five of colorful fibers (BRS SAFIRA, BRSRUBI, BRS 200, BRS VERDE and BRS TOPAZIO), the plant height $(\mathrm{cm})$, final stand $\left(n^{\circ}\right.$ plants. $\left.h a^{-1}\right)$, cotton bolls weight (g) and seed cotton yield $\left(\mathrm{kg} \cdot \mathrm{ha}^{-1}\right)$. The results indicate significant variability by the $F$ test $(P<0.05)$ among the genotypes, in the two years of cultivation, for all characteristics analyzed. The BRS $200(99.50 \mathrm{~cm})$, BRS SAFIRA $(99.31 \mathrm{~cm})$ and BRS TOPAZIO $(99.24 \mathrm{~cm})$, stand out by growth compared to the others. The CNPA GO 2007-700 (39,250 plants. ha $\left.{ }^{-1}\right)$ had the highest population density, but was not the most productive. The BRS TOPAZIO (1,388.75 kg. ha $\left.\mathrm{H}^{-1}\right)$ had the highest seed cotton yields compared to the others. The evaluated genotypes have potential for cultivation in the Agreste of Pernambuco; however, more studies need to be conducted to recommend the most productive and adapted to the region.

KEYWORDS: Rainfed farming, agroenergy, cotton cultivation. 


\section{Introdução}

A cultura do algodão (Gossypium hirsutum) possui grande importância socioeconômica para a região Semiárida do Brasil, seja através do beneficiamento de suas fibras para a indústria têxtil, ou do caroço, que é utilizado na produção de óleo e ração animal. Ademais, as folhas servem como uma importante fonte de proteína para a alimentação dos animais na época seca, principalmente se for fornecida com a palma forrageira. Existe ainda um mercado emergente para utilizar o algodão (caroço) na produção de biodiesel, e demandas da utilização de algodão orgânico e com fibras coloridas (CARDOSO et al., 2010; OLIVEIRA et al., 2006).

O cultivo dessa oleaginosa no Semiárido brasileiro está associado, historicamente, com a pecuária e o cultivo do milho e feijão pelos agricultores familiares. Apesar de o polo produtivo ter migrado para a região dos Cerrados, a região Semiárida do Nordeste possui condições edafoclimáticas favoráveis ao desenvolvimento dessa cultura em bases ecológicas (ALVES et al., 2010; OLIVEIRA et al., 2009).

O Agreste pernambucano encontra-se entre as regiões fisiográficas com potencial à exploração do algodão herbáceo, por apresentar condições climáticas favoráveis a partir do segundo decênio de março, onde a precipitação anual varia entre 500 e $1.500 \mathrm{~mm}$, e faixas de temperatura entre 18 e $30^{\circ} \mathrm{C}$, exigidos pela cultura (CORDÃO-SOBRINHO et al., 2015; SILVA; SILVA; AZEVEDO, 2012).

O Brasil é o terceiro maior produtor (27.258,00 mil toneladas) e o segundo maior exportador de algodão (847,5 mil toneladas) do mundo (ASSOCIAÇÃO..., 2018; MINISTÉRIO..., 2018). Estimativas indicam que na safra 2017-2018 foram colhidas 4.897,40 mil toneladas de algodão em caroço, 1.959,40 mil toneladas de algodão em pluma e 2.938,00 mil toneladas de caroço de algodão (ASSOCIAÇÃO..., 2018).

A região Nordeste do Brasil é a segunda maior produtora de algodão do país e contribui com $26 \%$ da produção nacional. Além do mais, o parque têxtil da região Nordeste é um dos maiores polos de consumo industrial de algodão da América Latina (OLIVEIRA et al., 2012; SINDA-ABRAPA, 2018).

O melhoramento genético do algodoeiro no Nordeste brasileiro destaca como prioridade a obtenção de cultivares produtivos, que sejam resistentes a pragas e doenças, que sejam adaptados às condições edafoclimáticas da região, e que possuam fibras especiais, finas, resistentes e que possuam várias colorações (ECHER et al., 2010; GILIO et al., 2017).

A região semiárida do Nordeste do Brasil é caracterizada por apresentar elevadas temperaturas diurnas e baixa temperaturas noturnas, alta radiação solar, baixa umidade do ar, baixa precipitação pluviométrica, com chuvas descontínuas, infrequentes, imprevisíveis, aleatórias, que se concentram em poucos meses. Os solos em sua grande maioria são rasos, com baixa capacidade de armazenamento de água, apresentam $\mathrm{pH}$ ácidos, drenagem insuficiente, em algumas localidades são salinizados, e com baixa disponibilidades de alguns nutrientes essenciais ao crescimento e desenvolvimento das plantas. Todas essas características limitam o cultivo das plantas e a criação de animais nessa área, com reflexo na economia regional e na qualidade de vida dos habitantes (ALVES et al., 2017).
As empresas produtoras de sementes vêm lançando no mercado nordestino inúmeros cultivares adaptados à região. A recomendação desses materiais aos agricultores deve ser precedida de uma avaliação nessa ampla região, visando fornecer maiores subsídios no tocante à escolha adequada de cultivares que devam ser utilizados. Para isso, uma rede de ensaios de cultivares de algodoeiro vêm sendo realizados pela Empresa Brasileira de Pesquisa Agropecuária e Instituto Agronômico de Pernambuco em diversos ambientes do Nordeste brasileiro com a finalidade de identificar aquelas de melhor comportamento produtivo e resistentes às adversidades locais (OLIVEIRA et al., 2009).

O objetivo deste trabalho foi avaliar o desempenho de genótipos de algodão herbáceo (Gossypium hirsutum), cultivados no Agreste de Pernambuco em sistema de sequeiro.

\section{Material e Métodos}

$\mathrm{O}$ experimento foi conduzido na Estação Experimental José Nilson de Melo, pertencente ao Instituto Agronômico de Pernambuco (IPA), localizada no município de Caruaru, Agreste de Pernambuco - Brasil, cujas coordenadas geográficas são: $08^{\circ} 14^{\prime} 18,2^{\prime \prime} \mathrm{S}$ e $35^{\circ} 54^{\prime} 57,1^{\prime \prime} \mathrm{W}$.

O clima da região, de acordo com a classificação de Thornthwaite, é do tipo Dd'a' (Semiárido megatérmico) com duas estações climáticas: uma chuvosa (março-agosto) e outra seca (setembro-fevereiro). A precipitação média anual, para anos normais, é de $640 \mathrm{~mm}$, umidade relativa média do ar de $67 \%$ e temperatura média anual de $23,5^{\circ} \mathrm{C}$ (MARTINS et al., 2007). A precipitação do período de cultivo do algodão foi de $529,7 \mathrm{~mm}$ (2016) e de $391,2 \mathrm{~mm}$ (2017). A temperatura média foi de $22,7 \pm 5,9^{\circ} \mathrm{C}$ (2016), e $22,7 \pm 7,3^{\circ} \mathrm{C}$ (2017) (Tabela 1).

$\mathrm{O}$ solo da área do experimento é caracterizado como Neossolo regolítico (SILVA et al., 2016), com textura argilo-arenosa e apresenta as seguintes características na camada de 0 a $30 \mathrm{~cm}$ : $\mathrm{pH}\left(\mathrm{em}_{2} \mathrm{O}\right)=4,80 ; \mathrm{Al}$ trocável $\left(\mathrm{cmol}_{\mathrm{c}} \mathrm{dm}^{-3}\right)=0,35 ; \mathrm{Ca}\left(\mathrm{cmol}_{\mathrm{c}} \mathrm{dm}^{-3}\right)=2,10 ; \mathrm{Mg}\left(\mathrm{cmol}_{\mathrm{c}} \mathrm{dm}^{-3}\right)=0,65$; P-Mehlich $1\left(\mathrm{mg} \mathrm{dm}^{-3}\right)=27,00 ; \mathrm{K}\left(\mathrm{mg} \mathrm{dm}^{-3}\right)=26,0$; Matéria orgânica $=6,2\left(\mathrm{~g} \mathrm{dm}^{-3}\right) ; \mathrm{V}(\%)=88,92 ; \mathrm{m}(\%)=11,08$; Soma de bases $=2,81\left(\mathrm{cmol}_{\mathrm{c}} \mathrm{dm}^{-3}\right)$; CTC $=3,16\left(\mathrm{cmol}_{\mathrm{c}} \mathrm{dm}^{-3}\right)$; argila $=580,0 \mathrm{~g} \mathrm{~kg}^{-1}$, silte $=50,0 \mathrm{~g} \mathrm{~kg}^{-1} \mathrm{e}$ areia $=370,0 \mathrm{~g} \mathrm{~kg}^{-1}$.

$\mathrm{O}$ ensaio foi realizado entre os meses de maio e outubro nos anos de 2016 e 2017 , onde foram utilizados dez genótipos de algodão herbáceo (Gossypium hirsutum), sendo cinco de fibras brancas (BRS ARARIPE, CNPA 8H, CNPA GO 2006-1023, CNPA GO 2007-419 e CNPA GO 2007-700) e cinco de fibras coloridas (BRS SAFIRA, BRS RUBI, BRS 200, BRS VERDE, BRS TOPÁZIO).

O preparo do solo foi realizado com uma aração (até $30 \mathrm{~cm}$ de profundidade), sem gradagem. Na semeadura foram utilizadas quatro sementes a cada $0,25 \mathrm{~m}$ de sulco, sendo realizado o desbaste aos 10 dias após a emergência. Ao longo do cultivo foram realizadas duas capinas.

A adubação de plantio foi realizada manualmente, após a semeadura, próxima à linha de cultivo, a $15 \mathrm{~cm}$ do colo da planta, aplicando-se a fórmula 20-10-20 de N-P - K. A adubação de cobertura foi aplicada 30 dias após a emergência das plântulas, 
Tabela 1. Precipitação e temperatura do local de cultivo das variedades de algodão nos anos de 2016 e 2017.

\begin{tabular}{|c|c|c|c|c|c|c|c|c|c|c|c|c|c|}
\hline \multicolumn{14}{|c|}{ Precipitação (mm) } \\
\hline \multicolumn{14}{|c|}{2016} \\
\hline Jan & Fev & Mar & Abr & Mai & Jun & Jul & Ago & Set & Out & Nov & Dez & Total & Média \\
\hline 154,3 & 86,4 & 75,7 & 143,8 & 224,9 & 70,2 & 139,4 & 72,8 & 18,0 & 4,4 & 32,6 & 0,3 & $1.022,8$ & 85,23 \\
\hline \multicolumn{14}{|c|}{$\begin{array}{c}\text { Precipitação do período de cultivo (Maio/Out) } \\
529,7 \mathrm{~mm}\end{array}$} \\
\hline \multicolumn{14}{|c|}{2017} \\
\hline Jan & Fev & Mar & Abr & Mai & Jun & Jul & Ago & Set & Out & Nov & Dez & Total & Média \\
\hline 12,8 & 17,4 & 35,7 & 144,3 & 42,1 & 122,3 & 122,4 & 58,9 & 14,9 & 30,6 & 43,5 & 12,2 & 657,1 & 54,76 \\
\hline \multicolumn{14}{|c|}{$\begin{array}{l}\text { Precipitação do periodo de cultivo (Maio/Out) } \\
391,2 \mathrm{~mm}\end{array}$} \\
\hline \multicolumn{14}{|c|}{ Temperatura $\left({ }^{\circ} \mathrm{C}\right)$} \\
\hline \multicolumn{14}{|c|}{2016} \\
\hline Jan & Fev & Mar & Abr & Mai & Jun & Jul & Ago & Set & Out & Nov & Dez & & \\
\hline $\begin{array}{l}25,2 \\
\pm 9,6\end{array}$ & $\begin{array}{l}24,6 \\
\pm 8,8\end{array}$ & $\begin{array}{r}25,3 \\
\pm 10,3\end{array}$ & $\begin{array}{l}24,9 \\
\pm 9,8\end{array}$ & $\begin{array}{l}23,2 \\
\pm 7,4\end{array}$ & $\begin{array}{l}22,5 \\
\pm 6,1\end{array}$ & $\begin{array}{l}21,3 \\
\pm 6,1\end{array}$ & $\begin{array}{l}22,2 \\
\pm 8,8\end{array}$ & $\begin{array}{l}22,5 \\
\pm 8,6\end{array}$ & $\begin{array}{l}24,6 \\
\pm 9,6\end{array}$ & $\begin{array}{l}24,6 \\
\pm 9,3\end{array}$ & $\begin{array}{c}25,4 \\
\pm 10,5\end{array}$ & & \\
\hline \multicolumn{14}{|c|}{$\begin{array}{l}\text { Temperatura média do periodo de cultivo (Maio/Out) } \\
\qquad 22,7 \pm 5,9^{\circ} \mathrm{C}\end{array}$} \\
\hline \multicolumn{14}{|c|}{2017} \\
\hline Jan & Fev & Mar & Abr & Mai & Jun & Jul & Ago & Set & Out & Nov & Dez & & \\
\hline $\begin{array}{c}26,0 \\
\pm 10,2\end{array}$ & $\begin{array}{l}25,7 \\
\pm 8,9\end{array}$ & $\begin{array}{l}26,5 \\
\pm 8,9\end{array}$ & $\begin{array}{c}27,0 \\
\pm 11,3\end{array}$ & $\begin{array}{l}24,0 \\
\pm 8,5\end{array}$ & $\begin{array}{l}21,8 \\
\pm 9,1\end{array}$ & $\begin{array}{l}23,1 \\
\pm 8,6\end{array}$ & $\begin{array}{l}21,3 \\
\pm 8,1\end{array}$ & $\begin{array}{c}21,3 \\
\pm 13,2\end{array}$ & $\begin{array}{l}24,5 \\
\pm 9,8\end{array}$ & $\begin{array}{l}24,0 \\
\pm 9,1\end{array}$ & $\begin{array}{l}25,7 \\
\pm 9.8\end{array}$ & & \\
\hline \multicolumn{14}{|c|}{$\begin{array}{l}\text { Temperatura média do periodo de cultivo (Maio/Out) } \\
\qquad 22,7 \pm 7,3{ }^{\circ} \mathrm{C}\end{array}$} \\
\hline
\end{tabular}

com adição de nitrogênio (60 kg.ha-1), segundo a recomendação de adubação para o estado de Pernambuco, após análise do solo do local do cultivo (CAVALCANTI, 1998).

O delineamento estatístico utilizado foi blocos casualizados com quatro repetições e dez tratamentos (genótipos de algodão). As parcelas experimentais foram constituídas por quatro fileiras de 5,0 m lineares em espaçamento de 0,80 m entre linhas e 0,25 m entre plantas, com 4 plantas/m linear, perfazendo 20 plantas por fileira e tendo como área útil as duas linhas centrais.

No final do experimento, aos 185 dias após o plantio, tanto no ano de 2016 quanto no ano de 2017 foram determinadas características agronômicas por meio da altura média das plantas $(\mathrm{cm})$, estande final $\left(\mathrm{n}^{\mathrm{o}}\right.$ plantas.ha $\left.\mathrm{a}^{-1}\right)$, peso do capulho (g) e rendimento de algodão em caroço $\left(\mathrm{kg} \cdot \mathrm{ha}^{-1}\right)$.

A variável altura de planta foi determinada pela distância média entre o nível do solo e a gema apical da planta. O estande final, pela quantidade total de plantas existentes na época da colheita. Por ocasião da colheita, foram escolhidos os 20 capulhos de cada fileira da área útil, no terço médio da planta, para posterior definição do peso médio de um capulho. O rendimento de algodão em caroço, estabelecido pela produção das duas linhas centrais de cada parcela experimental (área útil), extrapolado para quilogramas por hectare.

A herdabilidade no sentido amplo foi calculada pelo estimador: $\mathrm{h}^{2}=\sigma_{\mathrm{g}}^{2} / \sigma_{\mathrm{p}}^{2}$ × 100; onde: $\sigma_{\mathrm{g}}^{2}=$ variância genética, e $\sigma_{\mathrm{p}}^{2}=$ variância fenotípica. A variância genética foi calculada pelo estimador $\sigma_{\mathrm{g}}^{2}=$ MSTreat - MSRes $/ \mathrm{J}$; onde: MSTreat $=$ média do quadrado do tratamento; MSRes = média do quadrado do resíduo e $\mathrm{J}$ = número de repetições (ALVES et al., 2016a).

Os dados foram submetidos à análise de variância pelo teste F, e as médias comparadas pelo teste de Tukey ao nível de $5 \%$ de probabilidade. As correlações entre as características agronômicas foram obtidas como descritos por Alves et al. (2016a), foi testada a probabilidade de 1 e $5 \%$ pelo teste t. Utilizaram-se para análise dos dados os programas estatísticos SISVAR ${ }^{\circledR}$ (SILVA; AZEVEDO, 2016) e GENES ${ }^{\circledR}$ - Genética Quantitativa e Estatística Experimental, versão 2013.5.1 (CRUZ, 2006).

\section{Resultados e Discussão}

Os dados da variável altura final de plantas dos dez genótipos de algodão herbáceo, cultivados no município de Caruaru nos anos de 2016 e 2017, estão descritos na Tabela 2. Os resultados indicam variabilidade significativa pelo teste $\mathrm{F}(\mathrm{P}<0,05)$ entre os genótipos nos dois anos de cultivo para essa característica.

No ano de 2016, os genótipos BRS TOPÁZIO $(95,75 \mathrm{~cm})$, CNPA GO 2006-1023 (93,75 cm) e BRS SAFIRA $(92,25 \mathrm{~cm})$ foram os que cresceram mais em comparação aos outros genótipos. Em 2017, o BRS $200(109,00 \mathrm{~cm})$, BRS SAFIRA $(106,36 \mathrm{~cm})$ e BRS RUBI $(105,61 \mathrm{~cm})$ se destacaram pela sua altura em comparação aos demais (Tabela 2). A resposta diferenciada do crescimento entre os genótipos nos dois anos 
de cultivo é esperada, tendo em vista a variabilidade genética, climática e ambiental do local de cultivo.

A altura das plantas nos dois anos de cultivo foi inferior aos relatados pela Embrapa para cada genótipo (VITAL-NETO et al., 2006; VALE et al., 2011; RIBEIRO et al., 2012), a amplitude de variação da altura da cultura do algodão é de 106 a $149 \mathrm{~cm}$, bem inferior aos obtidos neste ensaio, que variam de 61,60 a $109,00 \mathrm{~cm}$. No entanto, mantém-se dentro do esperado, uma vez que o crescimento vegetativo é influenciado pelo status hídrico e nutricional das células vegetais (TAIZ et al., 2017). Além disso, os fatores bióticos e abióticos, e os diferentes tratos culturais realizados na cultura do algodão, em cada local de cultivo, são particulares, e influenciam diretamente o crescimento das plantas. Apesar de o crescimento das plantas ter sido inferior, essa característica não está correlacionada ao estande, peso do capulho e rendimento. Além do mais, o crescimento excessivo das plantas pode representar um maior autossombreamento entre plantas e provocar redução na produtividade da cultura, podendo ser uma característica indesejável (CUNHA et al., 2016; SILVA et al., 2011; SILVA et al., 2013).

A razão entre o coeficiente de variação genético $(\mathrm{CVg})$ e o ambiental $(\mathrm{CVe})$, para a variável altura final das plantas, ficou abaixo de um, com valores de herdabilidade $\left(h^{2}\right)$ de 72,50 e 78,52\% (Tabela 2). Queiroz (2017), avaliando 21 genótipos de algodão, relata valor de $61,25 \%$ para a herdabilidade para essa característica, e valores abaixo de um para a razão $\mathrm{CVg} / \mathrm{CVe}$. O que comprova o domínio do ambiente na variabilidade dessa característica entre os genótipos.

Na Tabela 3 estão os dados do estande final dos dez genótipos de algodão herbáceo cultivados no município de Caruaru nos anos de 2016 e 2017. Os resultados indicam variabilidade significativa pelo teste $\mathrm{F}(\mathrm{P}<0,05)$ entre os genótipos nos dois anos de cultivo para essa característica. O estande das plantas de todos os genótipos de algodão foi reduzido nos dois anos de cultivo. No primeiro ano do ensaio, os estandes foram reduzidos em média $36 \%$, e no segundo ano $31 \%$. Essa redução é esperada tendo em vista a não germinação e estabelecimento de algumas plantas, por causa da pureza, sanidade, viabilidade e vigor da semente, ou pelo ataque de pragas, doenças e competição com as ervas daninhas, comuns em plantios em condições de campo.

O CNPA GO 2007-700 (40.750 plantas.ha ${ }^{-1}$ ) e BRS 200 (41.500 plantas.ha ${ }^{-1}$ ) foram os que tiveram os maiores números de plantas nos estandes em comparação aos outros genótipos (Tabela 3). Apesar do maior número de plantas no estande dos genótipos CNPA GO 2007-700 e BRS 200 em comparação aos outros, eles não foram os mais produtivos, indicando maior adaptabilidade desses genótipos, em comparação aos outros, às condições abióticas e bióticas do local de cultivo. Uma maior retenção de frutos e menor ataque de pragas e doenças foram relatados quando plantas de algodão herbáceo são cultivadas
Tabela 2. Altura final dos dez genótipos de algodoeiro herbáceo cultivados no município de Caruaru nos anos de 2016 e 2017.

\begin{tabular}{|c|c|c|}
\hline \multirow{3}{*}{ Genótipos } & \multicolumn{2}{|c|}{ Altura final } \\
\hline & 2016 & 2017 \\
\hline & \multicolumn{2}{|c|}{$\mathrm{cm}$} \\
\hline BRS ARARIPE & $73,50 \mathrm{abA}$ & 84,16 abcA \\
\hline CNPA 8H & $62,75 \mathrm{bA}$ & $61,60 \mathrm{cA}$ \\
\hline CNPA GO 2006-1023 & 93,75 aA & 67,96 bcB \\
\hline CNPA GO 2007-419 & $77,00 \mathrm{abA}$ & 98,22 abcA \\
\hline CNPA GO 2007-700 & $73,00 \mathrm{abA}$ & 89,28 abcA \\
\hline BRS SAFIRA & $92,25 \mathrm{aA}$ & 106,36 aA \\
\hline BRS RUBI & 78,25 abB & 105,61 aA \\
\hline BRS 200 & 90,00 abA & $109,00 \mathrm{aA}$ \\
\hline BRS VERDE & 88,50 abA & 96,35 abcA \\
\hline BRS TOPÁZIO & 95,75 aA & 102,73 abA \\
\hline Média & 82,48 & 92,13 \\
\hline$C V g(\%)$ & 11,41 & 15,79 \\
\hline CVe (\%) & 14,05 & 16,51 \\
\hline $\mathrm{CVg} / \mathrm{CVe}$ & $\mathbf{0 , 8 1}$ & 0,96 \\
\hline$h^{2}(\%)$ & 72,50 & 78,52 \\
\hline$D M S$ & 28,19 & $\mathbf{3 7 , 0 0}$ \\
\hline
\end{tabular}

Médias seguidas de letras minúsculas iguais na mesma coluna em relação aos genótipos não diferem entre si a $5 \%$ de probabilidade, pelo teste de Tukey. Letras maiúsculas iguais na mesma linha em relação aos períodos não diferem entre si a $5 \%$ de probabilidade, pelo teste de Tukey. $C V g$ - coeficiente de variação genético; $\mathrm{CVe}$ - coeficiente de variação ambiental; $h^{2}$ - herdabilidade no sentido amplo; $D M S$ - Diferença Mínima Significativa.
Tabela 3. Estande final das plantas dos dez genótipos de algodoeiro herbáceo cultivados no município de Caruaru nos anos de 2016 e 2017.

\begin{tabular}{|c|c|c|}
\hline \multirow{3}{*}{ Genótipos } & \multicolumn{2}{|c|}{ Estande final } \\
\hline & 2016 & 2017 \\
\hline & \multicolumn{2}{|c|}{$\overline{n^{o} \text { plantas.h }} a^{-1}(x$ 1000) } \\
\hline BRS ARARIPE & 32,00 abA & 31,00 aA \\
\hline CNPA 8H & $26,25 \mathrm{bA}$ & $27,00 \mathrm{aA}$ \\
\hline CNPA GO 2006-1023 & $37,50 \mathrm{abA}$ & 27,75 aA \\
\hline CNPA GO 2007-419 & 34,75 abA & 39,00 aA \\
\hline CNPA GO 2007-700 & 40,75 aA & 37,75 aA \\
\hline BRS SAFIRA & 29,75 abA & 32,75 aA \\
\hline BRS RUBI & 27,75 abA & 27,75 aA \\
\hline BRS 200 & $30,00 \mathrm{abB}$ & $41,50 \mathrm{aA}$ \\
\hline BRS VERDE & $26,25 \mathrm{bA}$ & 37,50 aA \\
\hline BRS TOPÁZIO & 33,75 abA & 37,75 aA \\
\hline Média & 31,87 & 33,98 \\
\hline $\mathrm{CVg}(\%)$ & 12,03 & 13,12 \\
\hline $\mathrm{CVe}(\%)$ & 18,50 & 17,60 \\
\hline $\mathrm{CVg} / \mathrm{CVe}$ & 0,65 & 0,75 \\
\hline$h^{2}(\%)$ & 62,85 & 68,97 \\
\hline$D M S$ & 14,34 & 14,55 \\
\hline
\end{tabular}

Médias seguidas de letras maiúsculas iguais na mesma linha em relação aos períodos não diferem entre si a $5 \%$ de probabilidade, pelo teste de Tukey. Letras minúsculas iguais na mesma coluna em relação aos genótipos não diferem entre si a $5 \%$ de probabilidade, pelo teste de Tukey. $C V g$ - coeficiente de variação genético; $C V e$ - coeficiente de variação ambiental; $h^{2}$ - herdabilidade no sentido amplo; DMS - Diferença Mínima Significativa. 
Tabela 4. Peso do capulho dos dez genótipos de algodoeiro herbáceo cultivados no município de Caruaru nos anos de 2016 e 2017.

\begin{tabular}{|c|c|c|}
\hline \multirow{3}{*}{ Genótipos } & \multicolumn{2}{|c|}{ Peso do capulho } \\
\hline & 2016 & 2017 \\
\hline & \multicolumn{2}{|c|}{$g$} \\
\hline BRS ARARIPE & $5,43 \mathrm{aB}$ & $6,60 \mathrm{bA}$ \\
\hline CNPA 8H & 5,07 aB & 6,99 abA \\
\hline CNPA GO 2006-1023 & 5,43 aA & $5,79 \mathrm{bA}$ \\
\hline CNPA GO 2007-419 & $5,45 \mathrm{aB}$ & 7,19 abA \\
\hline CNPA GO 2007-700 & $4,83 \mathrm{abA}$ & 7,59 abA \\
\hline BRS SAFIRA & $4,84 \mathrm{aB}$ & 7,36 abA \\
\hline BRS RUBI & $3,94 \mathrm{cB}$ & 8,78 aA \\
\hline BRS 200 & $4,19 \mathrm{bcB}$ & $6,35 \mathrm{bA}$ \\
\hline BRS VERDE & $5,08 \mathrm{aB}$ & 7,51 abA \\
\hline BRS TOPÁZIO & $4,94 \mathrm{aB}$ & 7,68 abA \\
\hline Média & 4,92 & 7,18 \\
\hline$C V g(\%)$ & 10,07 & 10,07 \\
\hline $\mathrm{CVe}(\%)$ & 5,48 & 10,98 \\
\hline $\mathrm{CVg} / \mathrm{CVe}$ & 1,84 & 0,92 \\
\hline$h^{2}(\%)$ & 93,11 & 77,08 \\
\hline$D M S$ & 0,66 & 1,92 \\
\hline
\end{tabular}

Médias seguidas de letras maiúsculas iguais na mesma linha em relação aos períodos não diferem entre si a $5 \%$ de probabilidade, pelo teste de Tukey. Letras minúsculas iguais na mesma coluna em relação aos genótipos não diferem entre si a $5 \%$ de probabilidade, pelo teste de Tukey. $\mathrm{CVg}$ - coeficiente de variação genético; $\mathrm{CVe}$ - coeficiente de variação ambiental; $h^{2}$ - herdabilidade no sentido amplo; $D M S$ - Diferença Mínima Significativa.

em menores densidade (SILVA et al., 2009). Além do mais, menores populações de plantas de algodoeiro são recomendadas quando esta oleaginosa for cultivada em locais sujeitos ao déficit hídrico (CHIAVEGATO; BERNARDES; CARVALHO, 2014).

A razão entre o coeficiente de variação genético $(\mathrm{CVg})$ e o ambiental (CVe), para a variável estande final, ficou abaixo de um, com valores de herdabilidade $\left(\mathrm{h}^{2}\right)$ de 62,85 e $68,97 \%$ (Tabela 3). O que comprova o domínio do ambiente na variabilidade dessa característica entre os genótipos.

O resultado do peso do capulho dos dez genótipos de algodoeiro herbáceo cultivados no município de Caruaru nos anos de 2016 e 2017, encontra-se na Tabela 4. Os resultados indicam variabilidade significativa pelo teste $\mathrm{F}(\mathrm{P}<0,05)$ no peso dos capulhos entre os genótipos e o ano de cultivo. No ano de 2016, os genótipos BRS RUBI (3,94 g) e BRS 200 (4,19 g) obtiveram a menor densidade dos capulhos em comparação aos demais, que não se diferenciaram estatisticamente. No ano de 2017, o BRS RUBI (8,78 g) foi o que obteve a maior densidade dos capulhos entre os genótipos. Mais uma vez, observa-se a variabilidade nas respostas entre os genótipos nas condições ambientais. O maior peso do capulho no ano de 2017 provavelmente deve-se à menor pluviosidade do período de cultivo das plantas, que foi $391,20 \mathrm{~mm}$, em comparação ao ano de 2016, que foi $529,70 \mathrm{~mm}$. Isso acontece pelo fato de o aumento da densidade causado pelo menor volume celular provocado pela menor quantidade de água nos tecidos.
Tabela 5. Rendimento de algodão em caroço dos dez genótipos de algodoeiro herbáceo cultivados no município de Caruaru nos anos de 2016 e 2017.

\begin{tabular}{|c|c|c|}
\hline \multirow{3}{*}{ Genótipos } & \multicolumn{2}{|c|}{ Rendimento } \\
\hline & 2016 & 2017 \\
\hline & \multicolumn{2}{|c|}{ kg.hat } \\
\hline BRS ARARIPE & 827,50 abA & $1.080,00 \mathrm{abA}$ \\
\hline CNPA 8H & $645,00 \mathrm{bA}$ & 997,50 bA \\
\hline CNPA GO 2006-1023 & $1.460,00 \mathrm{aA}$ & $1.192,50 \mathrm{abA}$ \\
\hline CNPA GO 2007-419 & 950,00 abB & $1.762,50 \mathrm{aA}$ \\
\hline CNPA GO 2007-700 & 852,50 abA & $1.062,50 \mathrm{abA}$ \\
\hline BRS SAFIRA & $1.107,50 \mathrm{abA}$ & $1.060,00 \mathrm{abA}$ \\
\hline BRS RUBI & 812,50 abA & $1.280,00 \mathrm{abA}$ \\
\hline BRS 200 & $715,00 \mathrm{bA}$ & $1.090,00 \mathrm{abA}$ \\
\hline BRS VERDE & 940,00 abA & $1.240,00 \mathrm{abA}$ \\
\hline BRS TOPÁZIO & $1.140,00 \mathrm{abA}$ & $1.637,50 \mathrm{abA}$ \\
\hline Média & 945,00 & $1.240,25$ \\
\hline $\mathrm{CVg}(\%)$ & 19,91 & 17,08 \\
\hline $\mathrm{CVe}(\%)$ & 31,05 & 24,14 \\
\hline $\mathrm{CVg} / \mathrm{CVe}$ & 0,64 & 0,71 \\
\hline$h^{2}(\%)$ & 62,19 & 66,69 \\
\hline$D M S$ & 713,77 & 728,28 \\
\hline
\end{tabular}

Médias seguidas de letras maiúsculas iguais na mesma linha em relação aos períodos não diferem entre si a $5 \%$ de probabilidade, pelo teste de Tukey. Letras minúsculas iguais na mesma coluna em relação aos genótipos não diferem entre si a $5 \%$ de probabilidade, pelo teste de Tukey. $C V g$ - coeficiente de variação genético; $C V e$ - coeficiente de variação ambiental; $h^{2}$ - herdabilidade no sentido amplo; $D M S$ - Diferença Mínima Significativa.

No ano de 2016, a razão entre o coeficiente de variação genético $(\mathrm{CVg})$ e o ambiental $(\mathrm{CVe})$, para a variável peso do capulho, ficou acima de um, com valor de herdabilidade $\left(\mathrm{h}^{2}\right)$ de 93,11 (Tabela 4), indicando alto controle genético para essa característica. No entanto, no ano de 2017, a razão entre o coeficiente de variação genético (CVg) e o ambiental (CVe), para essa variável, ficou abaixo de um, com herdabilidade $\left(\mathrm{h}^{2}\right)$ de 77,08 (Tabela 4). O que indica o domínio do ambiente na variabilidade dessa característica entre os genótipos. Queiroz (2017), avaliando 21 genótipos de algodão, relata valor de $92,39 \%$ para a herdabilidade para essa característica, e valores acima de um para a razão $\mathrm{CVg} / \mathrm{CVe}$.

$\mathrm{Na}$ Tabela 5, estão os dados de rendimento de algodão em caroço dos dez genótipos de algodoeiro herbáceo cultivados no município de Caruaru nos anos de 2016 e 2017. Os resultados indicam variabilidade significativa pelo teste $F(P<0,05)$ no rendimento de algodão em caroço entre os genótipos e o ano de cultivo. O CNPA GO 2006-1023 (1.460,00 kg.ha- $\left.{ }^{-1}\right)$ e o CNPA GO 2007-419 (1.762,50 kg.ha-1) foram os genótipos que se destacaram em relação aos outros, com os maiores rendimentos de algodão em caroço nos anos de 2016 e 2017 , respectivamente.

A razão entre o coeficiente de variação genético $(\mathrm{CVg})$ e o ambiental (CVe), para a variável rendimento de algodão em caroço, ficou abaixo de um, com valores de herdabilidade $\left(h^{2}\right)$ de 62,19 e $66,69 \%$ (Tabela 5). Queiroz (2017), avaliando 
21 genótipos de algodão, relata valor de $57,85 \%$ para a herdabilidade para essa característica, e valores abaixo de um para a razão $\mathrm{CVg} / \mathrm{CVe}$. O que comprova o domínio do ambiente na variabilidade dessa característica entre os genótipos.

Apesar da identificação de diferenças significativas pelo teste $\mathrm{F}(\mathrm{P}<0,05)$, entre os genótipos para todas as características avaliadas (altura final, estande final, peso do capulho e rendimento de algodão em caroço) nos dois anos de cultivo (2016 e 2017), e o reconhecimento das diferenças significativas entre os anos de cultivo influenciando as características de alguns genótipos individualmente, não é possível recomendar um genótipo superior aos outros, seja no aspecto produtivo ou adaptado às condições bióticas e abióticas do local de cultivo. No entanto, a análise conjunta desses ensaios identifica três genótipos que se destacam entre os demais, no aspecto resistência aos fatores bióticos e abióticos do local de cultivo - estande e altura final - e produtividade acima da média dos ensaios: CNPA GO 2006-1023, CNPA GO 2007-419 e BRS TOPÁZIO (Tabela 6).

Apesar de a diferença pluviométrica dos períodos de cultivo ser significativa, 529,70 mm (2016) e 391,2 mm (2017), não se observa relação positiva entre a produção de algodão em caroço e o regime pluviométrico. Provavelmente pelo fato de as plantas estarem em uma condição favorável de cultivo. Um regime pluviométrico de 400 a $700 \mathrm{~mm}$ por ciclo é condição favorável para que a cultura do algodão mantenha suas necessidades hídricas, dependendo das condições climáticas e da duração do ciclo do cultivar (ALVES et al., 2010).

No entanto, para que a cultura expresse todo o seu potencial produtivo, um suprimento hídrico maior é requerido (ZONTA et al., 2015), pois estimulará tanto o crescimento dos ramos vegetativos quanto dos ramos frutíferos, resultando em elevadas produtividades (BRITO et al., 2011). O potencial de rendimento do algodoeiro submetido a um manejo de irrigação racional pode alcançar 6,0 t.ha ${ }^{-1}$ de algodão em caroço (ZONTA et al., 2016). Além do mais, a maior disponibilidade e o acúmulo de água nos tecidos vegetais do algodoeiro resultam na maior síntese e acúmulo de carboidratos na planta (ALVES et al., 2016b).

Entretanto, as maiores produtividades foram detectadas em 2017, ano mais seco. Provavelmente, essa maior produção deve-se à maior densidade do capulho e das fibras ocasionada pelo déficit hídrico, que reduz o volume e aumenta a massa celular (YEATES, 2014). Maior produtividade e uso eficiente da água foram relatados quando as plantas de algodão são submetidas a menores volumes de água ( $28 \%$ da água disponível à planta) com maior frequência de irrigação (YEATES; ROBERTS; RICHARDS, 2010). O déficit hídrico em determinadas fases do ciclo de cultivo do algodoeiro causa severos danos, afetando as estruturas reprodutivas e, consequentemente, perda na produtividade. Esse evento aconteceu no ano de 2016, quando a falta de umidade no solo após a emissão da primeira maçã e da primeira flor causou severos danos na produção do algodão. No entanto, quando essa falta de umidade no solo se dá nas fases de crescimento inicial, após a emissão do primeiro botão floral e após a abertura do primeiro capulho, a perda de produtividade não é significativa, fato ocorrido no ano de 2017 (GWATHMEY; LEIB; MAIN; 2011; ZONTA et al., 2017).

Os resultados deste trabalho colaboram com os relatados por Chiavegato et al. (2014), os quais demonstram que o menor estande de plantas ocasiona aumento do peso do capulho e, consequentemente, aumento de produção, possivelmente pelo deslocamento de nutrientes para o terço superior das plantas. Outro fator observado é a correlação negativa entre o aumento da população e a altura das plantas (CHIAVEGATO et al., 2014), apesar de a correlação entre as variáveis avaliadas não serem significativas neste estudo (Tabela 7).

Embora o cultivo do algodão na região Nordeste em sequeiro não seja competitivo em comparação às grandes áreas irrigadas do Centro-Oeste do país, a produção dos genótipos avaliados é satisfatória, podendo ser cultivados na região do Agreste Pernambucano. No entanto, estudos precisam ser

Tabela 6. Análise conjunta das variáveis altura final das plantas, estande final, peso do capulho e rendimento de algodão em caroço dos dez genótipos de algodoeiro herbáceo cultivados no município de Caruaru nos anos de 2016 e 2017.

\begin{tabular}{|c|c|c|c|c|}
\hline \multirow{2}{*}{ Genótipos } & Altura final & Estande final & Peso do capulho & Rendimento \\
\hline & $\mathrm{cm}$ & $n^{o}$ plantas. ha ${ }^{-1}(x$ 1000) & $g$ & kg.hat \\
\hline BRS ARARIPE & 78,83 bc & $31,50 \mathrm{ab}$ & 6,02 a & 953,75 ab \\
\hline CNPA 8H & $62,17 \mathrm{c}$ & $26,63 \mathrm{~b}$ & 6,03 a & 821,25 b \\
\hline CNPA GO 2006-1023 & 80,85 abc & $32,63 \mathrm{ab}$ & 5,61 a & $1.326,25 \mathrm{ab}$ \\
\hline CNPA GO 2007-419 & 87,61 ab & 36,88 ab & 6,32 a & $1.356,25 \mathrm{ab}$ \\
\hline CNPA GO 2007-700 & 81,14 abc & 39,25 a & $6,21 \mathrm{a}$ & $957,50 \mathrm{ab}$ \\
\hline BRS SAFIRA & 99,31 a & 31,25 ab & 6,10 a & $1.083,75 \mathrm{ab}$ \\
\hline BRS RUBI & $91,93 \mathrm{ab}$ & $27,75 \mathrm{~b}$ & 5,73 a & $1.046,25 \mathrm{ab}$ \\
\hline BRS 200 & 99,50 a & 35,75 ab & 5,27 a & $902,50 \mathrm{ab}$ \\
\hline BRS VERDE & $92,42 \mathrm{ab}$ & 31,88 ab & $6,30 \mathrm{a}$ & $1.090,00 \mathrm{ab}$ \\
\hline BRS TOPÁZIO & 99,24 a & $35,75 \mathrm{ab}$ & $6,31 \mathrm{a}$ & $1.388,75$ a \\
\hline Média & 87,30 & 32,93 & 5,99 & $1.092,63$ \\
\hline$D M S$ & 20,37 & 11,33 & 1,38 & 539,19 \\
\hline
\end{tabular}

Médias seguidas de letras iguais na mesma coluna em relação aos genótipos não diferem entre si a 5\% de probabilidade, pelo teste de Tukey; $D M S$ - Diferença Mínima Significativa. 
Tabela 7. Correlação entre as variáveis altura final das plantas, estande final, peso do capulho e rendimento de algodão em caroço dos dez genótipos de algodoeiro herbáceo cultivados no município de Caruaru nos anos de 2016 e 2017 .

\begin{tabular}{|c|c|c|c|c|}
\hline Variáveis & Altura & Estande & $\begin{array}{l}\text { Peso do } \\
\text { capulho }\end{array}$ & Rendimento \\
\hline Altura & 1 & $-0,01 \mathrm{~ns}$ & $0,36 \mathrm{~ns}$ & 0,39 ns \\
\hline Estande & & 1 & $-0,08 n s$ & $0,26 \mathrm{~ns}$ \\
\hline $\begin{array}{l}\text { Peso do } \\
\text { capulho }\end{array}$ & & & 1 & $0,36 \mathrm{~ns}$ \\
\hline Rendimento & & & & 1 \\
\hline
\end{tabular}

ns: não significativo pelo teste t.

conduzidos em outras áreas para recomendação dos cultivares mais produtivos e que sejam resistentes aos estresses bióticos e abióticos para cada local de cultivo. Vale salientar que, apesar de alguns genótipos não estarem disponíveis no mercado, e de alguns não estarem no zoneamento agrícola para o estado de Pernambuco, o resultado desse ensaio se justifica pelo fato do papel da pesquisa agropecuária em dar opções aos agricultores de cultivos de genótipos que sejam viáveis economicamente. Destaca-se também a importância do incentivo de termos nos nossos plantios de algodão vários genótipos plantados em uma mesma área ou região, prevenindo a perda de produção pelo ataque de pragas e doenças, e/ou pelos estresses de seca, temperatura elevada, deficiências nutricionais que ocorrem frequentemente no Semiárido do Nordeste brasileiro. O programa de melhoramento genético do algodão é contínuo e já tem lançado vários genótipos produtivos e resistentes aos principais problemas de nossa região. No entanto, não devemos esquecer os genótipos desenvolvidos e que não estão sendo mais recomendados pelo mercado, pois o valor genético desses materiais é imensurável para uma agricultura mais ecológica, sustentável, produtiva e socialmente justa.

\section{Conclusões}

Os genótipos avaliados apresentam variabilidade significativa entre si, nos dois anos de cultivo, para os parâmetros avaliados (altura, estande final de plantas, peso do capulho e rendimento de algodão em caroço).

O genótipo BRS TOPÁZIO foi o que teve o maior rendimento de algodão em caroço comparado aos outros, quando avaliado nos anos de 2016 e 2017.

\section{Referências}

ALVES, F. A. L. et al. Study of the genetic variability, correlation and importance of phenotypic characteristics in cactus pear (Opuntia and Nopalea). African Journal of Agricultural Research, Nigeria, v. 11, n. 31, p. 2849-2859, 2016 a.

ALVES, F. A. L. et al. Genetic diversity and seasonal chemical profile by ${ }^{1} \mathrm{H}$ NMR and cytotoxic activity in Opuntia and Nopalea genres. Journal of Medicinal Plants Research, Nigéria, v. 10, n. 40, p. 732-747, 2016b.
ALVES, F. A. L. et al. Chemical and nutritional variability of cactus pear cladodes, genera Opuntia and Nopalea. American Journal of Food Technology, New York, v. 12, n. 01, p. 25-34, 2017.

ALVES, W. W. A. et al. Métodos de determinação e níveis de água disponível no solo: efeito sobre a cultura do algodoeiro herbáceo. Revista Caatinga, Mossoró, v. 23, n. 4, p. 91-96, 2010.

ASSOCIAÇÃO BRASILEIRA DOS PRODUTORES DE ALGODÃO - ABRAPA. Algodão no Brasil. Brasília. Disponível em: $<$ http:// www.abrapa.com.br/Paginas/dados/algodao-no-brasil.aspx $>$. Acesso em: 08 jul. 2018.

BRITO, G. G. et al. Physiological traits for drought phenotyping in cotton. Acta Scientiarum Agronomy, Maringá, v. 33, n. 1, p. 117-125, 2011.

CARDOSO, G. D. et al. Períodos de interferência das plantas daninhas em algodoeiro de fibra colorida 'BRS Safira'. Revista Ciência Agronômica, Fortaleza, v. 41, n. 3, p. 456-462, 2010.

CAVALCANTI, F. J. A. Recomendações de adubação para o estado de Pernambuco: $2^{\circ}$ aproximação. Recife: IPA, 1998. 198 p.

CHIAVEGATO, E. J.; BERNARDES, M. S.; CARVALHO, H. D. R. Estratégias para melhorar o aproveitamento da luminosidade na cultura do algodão In: ECHER, F. R. (Ed.) O algodoeiro e os estresses abioticos: temperatura, luz, água e nutrientes. Cuiabá: Instituto Mato-Grossense do Algodão, 2014. v. 1, cap. 2, p. 43-62.

CORDÃO-SOBRINHO, F. P. et al. Fiber quality of upland cotton under different irrigation depths. Revista Brasileira de Engenharia Agrícola e Ambiental, Campina Grande, v. 19, n. 11, p. 1057-1063, 2015.

CRUZ, C. D. Programa Genes: Biometria. Viçosa: UFV, 2006. 382 p.

CUNHA, R. G. et al. Arranjo espacial e biorreguladores de crescimento na produtividade do milho. Revista de Ciências Agroambientais, Alta Floresta, v. 14, n. 2, p. 22-31, 2016.

ECHER, F. R. et al. Estresse hídrico induzido por manitol em cultivares de algodão. Revista Ciência Agronômica, Fortaleza, v. 41, n. 4, p.638-645, 2010.

GILIO, T. A. S. et al. Genetic divergence among cotton genotypes grown in the main season and off season. Revista Caatinga, Mossoró, v. 30, n. 2, p. 377-390, 2017.

GWATHMEY, C. O.; LEIB, B. G.; MAIN, C. L. Lint yield and crop maturity responses to irrigation in a short-season environment. The Journal of Cotton Science, Baton Rouge, v. 15, n. 1, p. 1-10, 2011.

MARTINS, E. F. P. et al. Curvas de índice de sítio para leucina [Leucaena leucocephata (Lam.) de Wit] no agreste de Pernambuco. Ciência Florestal, Santa Maria, v. 17, n. 4, p. 365-376, 2007.

MINISTÉRIO DA INDÚSTRIA, COMÉRCIO EXTERIOR E SERVIÇOS - MDIC. Exportação e importação geral. Brasília. Disponível em: <http://comexstat.mdic.gov.br/pt/geral>. Acesso em: 08 jul. 2018.

OLIVEIRA, I. R. et al. Recomendação de cultivares de algodão para cinco ambientes nos estados da Bahia e de Sergipe: Ensaios realizados no ano agrícola de 2005. Aracaju: Embrapa Tabuleiros Costeiros, 2006. 6 p. (Embrapa Tabuleiros Costeiros - Circular Técnica, 39).

OLIVEIRA, F. A. et al. Produção do algodoeiro em função da salinidade e tratamento de sementes com regulador de crescimento. Revista Ciência Agronômica, Fortaleza, v. 43, n. 2, p. 279-287, 2012.

QUEIROZ, D. R. Análise genética para caracteres agronômicos e tecnológicos de fibra em genótipos de algodoeiro herbáceo (Gossypium hirsutum L. var. latifolium Hutch.). 2017. 62 p. Dissertação (Mestrado em Ciências Agrárias) - Universidade Estadual da Paraíba, Campina Grande, 2017. 
RIBEIRO, J. L.; RIBEIRO, V. Q.; DE MORELLO, C. L.; FARIAS, F. J. C.; SUASSUNA, N. D.; SILVA-FILHO, J. L.; PEDROSA, M. $B$. Desempenho da cultura do algodoeiro herbáceo no município de Colinas, MA, nos anos agrícolas de 2008/2009, 2009/ $2010 \mathrm{e}$ 2010/2011. Teresina: Embrapa, 2012. 7 p. (Circular Técnico 229).

SILVA, C. A. D.; BELTRÃO, N. E. M.; FERREIRA, A. C. B.; SILVA, O. R. R. F.; SUASSUNA, N. D. Algodoeiro herbáceo em sistema de cultivo adensado atualidades e perspectivas. Campina Grande: Embrapa Algodão, 2009. 27 p.

SILVA, F. A. S.; AZEVEDO, C. A. V. The Assistat software version 7.7 and its use in the analysis of experimental data. African Journal of Agricultural Research, Nigéria, v. 11, n. 39, p. 3733-3740, 2016.

SILVA, G. et al. Crescimento e produção de cultivares de algodão herbáceo consorciados no Cariri Cearense. ACSA-Agropecuária Científica no Semi-Árido, Campina Grande, v. 9, n. 3, p. 104-109, 2013.

SILVA, I. P. F. et al. Estudo das fases fenológicas do algodão (Gossypium hirsutum, L.). Revista Científica Eletrônica de Agronomia, Garça, v. 20, n. 1, 2011.

SILVA, M. T.; SILVA, V. P. R.; AZEVEDO, P. V. O cultivo do algodão herbáceo no sistema de sequeiro no Nordeste do Brasil, no cenário de mudanças climática. Revista Brasileira de Engenharia Agrícola e Ambiental, Campina Grande, v. 16, n. 1, p. 80-91, 2012.

SILVA, N. G. M. et al. Effects of planting densityand organic fertilization doses on productive efficiency of cactos pear. Revista Caatinga, Mossoró, v. 29, n. 4, p. 976-983, 2016.

TAIZ, L. et al. Fisiologia e desenvolvimento vegetal. 6 . ed. Porto Alegre: Artmed, 2017. 858 p.

VALE, D. G.; GUIMARÃES, F. M.; OLIVEIRA, G. S.; CARDOSO, G. D.; ALVES, I.; SILVA, J. C. A.; SILVA, O. R. R. F.; CARTAXO, W. V.; CARVALHO, L. P. Algodão Colorido "Tecnologia Emprapa para a geração de emprego e renda na agricultura familiar do Brasil". Campina Grande: Embrapa, 2011. 2 p.

VITAL-NETO, F. C.; FREIRE, E. C.; ANDRADE, F. P.; FONSECA, R. G.; SANTOS, J. W.; ARAÚJO, G. P.; ASSUNÇÃO, J. H.; LUCENA, M. C. L.; GUIMARÃES, G. L. BRS Araripe -Cultivar de ciclo anual destinada ao semi-árido do nordeste do Brasil. Campina Grande: Emprapa, 2006. 2 p.

YEATES, S. Efeitos do estresse hídrico na fisiologia do algodoeiro. In: ECHER, F. R. (Ed.) O algodoeiro e os estresses abióticos: temperatura, luz, água e nutrientes. Cuiabá: Instituto Mato-Grossense do Algodão, 2014. v. 1, cap. 3, p. 63-78.

YEATES, S. J.; ROBERTS, J. M.; RICHARDS, Q. D. High insect protection GM Bt cotton changes crop morphology and response to water compared to non Bt cotton. In: AUSTRALIAN AGRONOMY CONFERENCE, 15.; Food security from sustainable agriculture. 2010, Lincoln, 2010. Proceedings... New Zealand: Australian Society of Agronomy. Disponivel em: <http://www.regional.org. $\mathrm{au} / \mathrm{au} / \mathrm{asa} / 2010 /$ crop-production/physiology-breeding/7046_yeatess. htm\#TopOfPage $>$. Acesso em: 20 nov.2017.

ZONTA, J. H. et al. Efeito da irrigação no rendimento e qualidade de fibras em cultivares de algodoeiro herbáceo. Revista Caatinga, Mossoró, v. 28, n. 4, p. 43-52, 2015.

ZONTA, J. H. et al. Manejo da irrigação do algodoeiro. Campina Grande: Embrapa Algodão, 2016. 8 p. (Embrapa Algodão - Circular Técnica, 139).

ZONTA, J. H. et al. Cotton response to water déficits at diferente growth stages. Revista Caatinga, Mossoró, v. 30, n. 4, p. 980-990, 2017.

Recebido: 10 jul. 2018 Aprovado: 04 dez. 2018 